\title{
The Influence of the Professional Stress on the Communicative Qualities of Teacher's Personality
}

\author{
Rezeda M. Khusainova ${ }^{1}$ \\ ${ }^{1}$ Kazan (Volga region) Federal University, Kazan, Russia \\ Correspondence: Rezeda M. Khusainova, Kazan (Volga region) Federal University, Kremlyovskaya Street 18, \\ Kazan, 420008, Russia.
}

Received: December 29, 2014

Accepted: January 22, 2015 Online Published: February 11, 2015

doi:10.5539/res.v7n4p124

URL: http://dx.doi.org/10.5539/res.v7n4p124

\begin{abstract}
Thematic justification of the teachers' professional stress research is due to the fact that its prevention is a significant problem of psychological services in education. The purpose of the article is to study the interplay between professional stress and communication characteristics of teacher's personality in the process of increasing the teaching experience. The main method of studying this issue is the ascertaining experiment. The professional stress is correlated both with communicative and emotional-personal indicators; it influences such indicators as emotional stability, sociability, courage, practicality and innovative ability of the teacher and his/her independence in the relationship. The main feature of teacher's interpersonal communication is the predominance of conflict-free attitude, agreement in contacts with others. The indicator "the level of professional stress" appears almost throughout the teacher's professional activity and it is backbone in two of the three intercorrelation matrixes composed according to the increase of teaching experience. The obtained results allow talking about a marked influence of professional stress on the quality of teacher's personality. Emotional stability is regarded as one of the factors to deal with stress. Immediate practical value has a generated group of methods to diagnose the level of occupational stress objectively and quickly in terms of monitoring of professionally significant qualities of the teacher's personality.
\end{abstract}

Keywords: professional stress, pedagogic activity, communicative features of the teacher's personality

\section{Introduction}

The interest in researching professional stress in the pedagogical activity has not ceased in recent decades. Numerous scientists' researches of the teacher's activity (Baranov, 1997; Mitina, 2004; Rogov, 1998, Judin, 2002; Belukhin, 1994) and aptitude of stress at the workplace (Baranov, 1997; Mitina, 2004) allow to confirm the thesis that the teacher's activity is one of those professions that top the list of professions constituting real risk of stress influence. A number of authors (Baranov, 1997; Mitina, 2004; Rogov, 1998) single out frustration, anxiety, exhaustion and burnout as stress display. They associate it with such peculiarities of the teacher's work as the perception and understanding of various simultaneous communications, teacher's interrelation with various social groups (pupils, their parents, colleagues) not only at the workplace but also outside school, the teacher's overloading with various reporting documents, constant off-hour work. Teacher's responsibility, overloading and complexity together with other peculiarities of the pedagogical activity stipulate not only the possibility of developing stress with teachers, but also specific peculiarities of its display in the teacher's personality. Therefore, Prokhorov (1991) colligates the teacher's work with arising of negative features in the teacher's character structure. Thus, there arose the question of how professional stress is associated with the teacher's personal, communicative peculiarities and whether this interrelation changes with an increase in pedagogical experience.

\section{Materials and Methods}

One hundred and thirty two teachers participated in the experiment. They had been priory divided into 3 groups according to their pedagogical activity experience: 0-10 years, 11-20 years, and 20-30 years. For diagnosis purposes the following methodologies were used: Professional stress scale (Rogov \& Fontana) meant for discovering stress level; "Interpersonal relations diagnosis" (methodology of Leary, Leforge, \& Sazek), multifactorial questionnaire of R. Cattell. 


\section{Results and Discussions}

The value of average stress indicators in all three groups corresponds to the moderate level. The average value of this test results is consistent with the data (Fedorenko \& Biktimirova, 2014; Khusainova, 2014) that indicates that teachers who have the working experience of more than 15 years have persistent stress and emotional burnout syndrome. A number of researches denominate importance of events for the personality, psychological estimate of the situation by the personality, personal meaning as various factors influencing stress resistance (Baranov, 1997; Siegrist, 1995a; Akhmetzyanova \& Nugmanova, 2014).

Hereafter we analyzed the group data received in accordance with the Diagnosis of interpersonal relations methodology. The analysis of results on group I and the interpretation of the average test indicators allowed us to make the following conclusions: according to all octants, average indicators do not exceed the critical value. The analysis of the standard maximum allowed to single out the following types of interpersonal relations that are urgent for the teachers of group 1: octant 1 (autocratic), octant 5 (obedient and timid), octant 7 (cooperating), and octant 8 (altruistic). The last three enumerated octants can be combined into one type of interpersonal relations that is characteristic of the prevalence of confirming affirmations, congruence in contacts with others (cooperating, altruistic), self-distrust, amenability to other's opinion, and a taste for compromises (obedient and timid). We think that autocratic type of interpersonal relations is more likely expressed in relations with pupils as this style of communication simplifies the teacher's work with pupils. Often young and inexperienced teachers follow this style by mistake without realizing that it restrains the education process and pupils' personal growth (Belukhin, 1994). The analysis of results according to group II displayed similar results. We fix standard maximum of indicators in octants 7 and 8 representing cooperating and altruistic type of interpersonal relations respectively. In group III the standard maximum is also fixed in octants 7 (cooperating) and 8 (altruistic). Therefore, the teacher's communication peculiarity is the prevalence of conforming affirmations, congruence in contacts with others.

The analysis of the average indicators according to the Cattell's test in group I determined that the teachers of this group have a tendency to high level of straightforwardness, self-control and anxiety. The analysis of average indicators according to the test in group I allows to fix a decrease in indicators of A (sociability), B (quick-wittedness), C (emotional robustness), E (subordination), F (seriousness), H (shyness), I (sensibility), L (suspiciousness), N (straightforwardness), O (anxiety), Q3 (high level of self-control) and Q4 (tonicity) factors. It allows to speak about changes in emotional-volitional peculiarities (C, I, O, Q3, Q4 factors) as well as communicative characteristics and peculiarities of interpersonal interrelation (A, H, F, E, N, L factors) that can cause narrowing circle of contacts, emotional distance from pupils, low self-esteem. In this regard, it is necessary to point at the factor that considerably influences the teacher's personality. It is gratification crisis regarded as a phenomenon that can cause fast growth of discontent with the activity results, disappointment and frustration (Siegrist, 1995a; Siegrist, 1996). They state its reason is the inconsistency between the made effort and received reward. The described changes in emotional and interpersonal relations areas can be a consequence of the continued stress influence on the teacher. Therefore, this group observes the stress display in changes in emotional condition of testees and their personal features. This group also displays a positive tendency. It is related to the teacher's professional growth. It is confirmed by the growth of the following factors: Q1 (tendency to innovations), Q2 (independence), M (pragmatism), G (expressed ego strength). The personality profile peak points according to teachers' group III allow us to characterize him as sociable, quick-witted, cruel, pragmatic, with a high level of self-control and tendency to innovations. However, at the same time such features as subordination, shyness and anxiety peep in his character.

In spite of the tendency of increase or decrease in some factors values, the majority of them remained within their pole - positive (+) or negative (-). A (sociability), L (suspiciousness) and Q4 (tonicity) factors happened to be categories that changed hardly. Considerable leaps of these factors indicators allow us to suppose that they indicate unfavorable changes related to the peculiarities of the pedagogic activity, and these are they that the correction work with teachers must rely on. In this regard, we think it is necessary to develop teachers' communicative anticipation. It is an anticipated sound person who can better orient in interpersonal relations, wider imagine and use the existing social roles and ways of their interrelation for receiving the necessary result, better solve interpersonal problems arising in the process of the pedagogic activity (Siegrist, 1996).

The next stage of our research was to define how emotional, communicative and personal features of the teacher are interrelated with the "professional stress level" indicator and what character the interrelations under study had. The interrelations between the indicators under study were analyzed with the aid of correlation pleads method. Intercorrelations matrixes were made for each of three testees' groups. 
In teachers' group I central system forming indicators include $\mathrm{C}$ factor (emotional robustness) -9 relations; octant 7 (cooperating type of interpersonal relations), professional stress level -6 relations each; Q3 (self-control), $\mathrm{F}$ (seriousness), 5 (obedient and timid type of interpersonal relations) factors and octants 8 (altruistic) -5 relations each. The indicator of "professional stress level" has opposite correlations with A (sociability) ( $\mathrm{p} \leq 0.05), \mathrm{C}$ (emotional robustness) ( $\mathrm{p} \leq 0.01), \mathrm{H}$ (courage) $(\mathrm{p} \leq 0.05), \mathrm{M}$ (pragmatism) $(\mathrm{p} \leq 0.05)$ factors. Accordingly, with an increase in the stress level, such personal features as emotional robustness, sociability, courage and pragmatism being significant for the teacher as a professional will change. The teachers of this group can control well their emotions and behavior. They are restrained in expressing their feelings, careful and lean in expressing their point of view, compliant, conforming, and oversensitive. We suppose that at this period the teacher uses his organism's adaptive capabilities, uses his energy optimally adapting to circumstances (Siegrist, 1996). Consequently, the work related to forming the teacher's emotional robustness will contribute to a decrease in the professional stress level.

System forming indicators that have the biggest number of relations in group II include octant 4 (distrustful and skeptical type of interpersonal relations) - 7 relations, "professional stress level", octant 1 (autocratic type of interpersonal relations) -6 relations, octant 8 (altruistic type of interpersonal relations) -5 relations, octant 5 (obedient and timid type of interpersonal relations), I (sensibility), Q4 (tonicity) factors -4 relations each; F (seriousness), C (emotional robustness) factors-3 relations each. We will mention in the analysis of the interrelations according to the indicator of the professional stress level that direct interrelations are referred to the indicators of Q4 factor (tonicity) at $\mathrm{p} \leq 0.01$. Octant 4 as a system forming indicator directly depends on MD (sincerity) ( $\mathrm{p} \leq 0.01)$, I (sensibility) ( $\mathrm{p} \leq 0.05), \mathrm{Q} 3$ (self-control) $(\mathrm{p} \leq 0.001)$ factors and is in direct correlation with $\mathrm{M}$ factor (pragmatism), octant 3 (aggressive). The analysis of indicators according to octant 4 allows to interpret the teacher of this group as a skeptic being non-confirming, realistic in views and actions, critical to the attitude to others. The tendency to restraint, secretiveness and suspiciousness to the others will increase if the indicators interrelated with this octant change (increase in case of direct correlation and decrease in case of inverse correlation).

The correlation analysis of the indicators interdependence in group III indicates that the system forming indicators in this group include F (seriousness) factor -6 relations, $\mathrm{O}$ (anxiety), E (subordination) factors, octant 5 (obedient and timid type of interpersonal relations) - 4 relations each. "Professional stress level" in this group has only one direct correlation with $\mathrm{O}$ indicator (anxiety) $(\mathrm{p} \leq 0.05)$. In the context of our research, $\mathrm{O}$ factor (anxiety) attracts our interest. It is in direct correlation with the professional stress level $(p \leq 0.05)$ and in reverse correlation with Q1 factor (tendency to innovations) ( $\mathrm{p} \leq 0.05)$ and octant 2 (independently dominating type of interpersonal relations) $(\mathrm{p} \leq 0.05)$. It means that the teachers' anxiety growth causes an increase in stress level and personal anxiety, negatively influences the teacher's innovation capabilities and his independence in relations. Besides, we ascertained a number of interrelations with A factor (sociability) that is in direct correlation with octants 7 (cooperating type of interpersonal relations) ( $\mathrm{p} \leq 0.05), 8$ (altruistic type of interpersonal relations) $(\mathrm{p} \leq 0.05)$ and in reverse correlation with octant 4 (distrustful and skeptical type of interpersonal relations) $(\mathrm{p} \leq 0.01)$. The growth of sociability at the increase in cooperation and altruism to others is as natural as the case when distrustful person stints himself in communication.

The comparison of correlation relationship according to three groups allows us to make some conclusions: persisting system forming indicators in groups I and II are "the level of professional stress", octant 8 (altruistic type of interpersonal relations), F (seriousness), C (emotional robustness), octant 5 (obedient and timid type of interpersonal relations) factors. The number of relations in group III is much less than in groups I and II. The system forming indicators that continued in group III include F (seriousness) factor, octant 5 (obedient and timid type of interpersonal relations).

\section{Conclusion}

Therefore, we have fixed that professional stress is related both to communicative and emotional and personal indicators. It negatively affects such indicators as emotional robustness, sociability, courage, pragmatism, innovation skills of the teacher and his independence in relations. We consider the use and analysis of the results of the author's program aimed to form the teachers' stress resistance to be a perspective direction of the research within the defined theme.

\section{Acknowledgments}

The work is performed according to the Russian Government Program of Competitive Growth of Kazan Federal University 


\section{References}

Akhmetzyanova, N. V., \& Nugmanova, D. R. (2014). Influence of Trainings on the Indicators of Sociopsychological Adaptation. Asian Social Science, 10(21), 250-255.

Baranov, A. A. (1997). Stress Resistance and Teacher's Masterfulness (p. 108). Izhevsk: Publishing house of the Udmurt University.

Belukhin, D. A. (1994). Teacher: From Love to Hatred (p. 140). Moscow: Public Education.

Fedorenko, M. V., \& Biktimirova, F. M. (2014). Age-related aspect of interrelations between life quality parameters and psychological peculiarities in a person with disabilities. Life Science Journal, 11(11s).

Judin, V. P. (2002). Organizational and Pedagogic Conditions of Teacher's Social Protection in Education (p. 482) (Thesis of PhD of Pedagogy, Educational institution of the Russian Academy of education, Institute of vocational education, Kazan).

Khusainova, R. M. (2014). Factors of Teachers' Psychological Health-Ailment within the Period of Their Professional Activity. World Applied Sciences Journal, 30(5), 608-611.

Mitina, L. M. (2004). Teacher's Labor and Professional Development Psychology (p. 320). Moscow: Academy.

Prokhorov, A. O. (1991). Self-Regulation of Mental State in Educational and Pedagogic Activity. Psychology Issues, 5, 156-161.

Rogov, E. I. (1998). Teacher as an Object of Psychological Research (p. 496). Moscow: VLADOS.

Siegrist, J. (1995). Emotions and health in occupational life: New scientific findings and policy implications. Patient Education and Counseling, 3, 227-236. http://dx.doi.org/10.1016/0738-3991(95)00805-A

Siegrist, J. (1996). Adverse health effects of high-effort/low-reward conditions. Journal of Occupational Health Psychology, 1(1), 27-41. http://dx.doi.org/10.1037/1076-8998.1.1.27

\section{Copyrights}

Copyright for this article is retained by the author(s), with first publication rights granted to the journal. This is an open-access article distributed under the terms and conditions of the Creative Commons Attribution license (http://creativecommons.org/licenses/by/3.0/). 